\title{
Harnessing the Power of Kiwifruit for Radiosensitization of Melanoma
}

\author{
LEON KOU ${ }^{1,2}$, ZIWEN ZHU $^{3}$, EMERSON FAJARDO ${ }^{3}$, QIAN BAI $^{3}$, CHASE REDINGTON $^{3}$, HUAPING XIAO $^{3}$, \\ MARCO LEQUIO ${ }^{2,3}$, NELSON SHAM ${ }^{2}$, MARK R. WAKEFIELD $^{3}$ and YUJIANG FANG ${ }^{2,3}$ \\ ${ }^{1}$ HCA Healthcare/USF Morsani College of Medicine GME/St. Petersburg \\ General Hospital, St. Petersburg, FL, U.S.A.; \\ ${ }^{2}$ Department of Microbiology, Immunology \& Pathology, \\ Des Moines University College of Osteopathic Medicine, Des Moines, IA, U.S.A.; \\ ${ }^{3}$ Department of Surgery, University of Missouri School of Medicine, Columbia, MO, U.S.A.
}

\begin{abstract}
Background: Melanoma is the deadliest variant of skin cancer and its incidence continues to increase. There are limited treatment options for advanced and metastatic cases of melanoma, despite advances in immunotherapy and chemotherapy. Melanoma is notorious as a radioresistant tumor. Previous studies found that phytochemicals, such as resveratrol and those found in green tea and blueberry, can sensitize various cancer cells, including melanoma, to radiotherapy. Our previous study also revealed that kiwifruit extract (KE) has antitumor activity to melanoma cells. This study was designed to expand upon our previous investigation and determine KE's potential as a radiosensitizer on CRL-11147 melanoma cancer cells and elucidate the possible mechanisms behind its potential. Materials and Methods: Proliferation and apoptosis of CRL11147 melanoma cells under radiation therapy $(R T)$ plus KE versus RT alone were investigated using Proliferative cell nuclear antigen (PCNA) staining, quick cell proliferation assay, clonogenic assay, and caspase-3 activity assay. Reverse transcription-polymerase chain reaction (RT-PCR) and immunohistochemistry (IHC) were then used to investigate the mechanisms behind the observed results. Results: The percentage of CRL-11147 colonies, PCNA staining intensity, and the optic density value of CRL-11147 cells decreased with RT/KE vs. RT alone. Relative caspase3 activity was increased with $R T / K E$ vs. RT alone. Increased
\end{abstract}

This article is freely accessible online.

Correspondence to: Dr. Yujiang Fang, Department of Microbiology \& Immunology, Des Moines University, IA 50312, U.S.A. Tel: +1 5152711435; Fax: +1 5152711543, e-mail: yujiang.fang@dmu.edu

Key Words: Kiwifruit, melanoma, TRAILR1, p27, proliferation, apoptosis, radiation. expression of the anti-proliferative molecule p27 and proapoptotic molecule TRAILRI correlated with the anti-tumor effect seen in the RT/KE group versus the RT alone group. Conclusion: KE augments radiosensitivity of CRL-11147 by up-regulating both p27 and TRAILR1 to inhibit proliferation and increase apoptosis, respectively.

While the incidence rate of all cancers combined has been declining, the incidence of melanoma continues to rise (1). Projections estimate that 112,000 new invasive melanomas will be diagnosed by 2030 at the current rate (1). Although the least common of all skin cancers, melanoma is the deadliest and responsible for nearly $75 \%$ of deaths (2). Treatment options include surgery, immunotherapy, radiotherapy (RT), and/or chemotherapy (2). Despite advances in immunotherapy and chemotherapy, treatments can be costly and have considerable side-effects and impact on quality of life (3-5). Because melanoma is notoriously radioresistant, $\mathrm{RT}$ is rarely a primary treatment in melanoma (6). However, RT plays important role in metastatic melanoma, where limited therapies are available $(6,7)$. Strategies to increase radiosensitivity of melanoma cells can increase the effectiveness and application of RT in melanoma treatment.

Kiwifruit has well-known antioxidant properties, such as reduction in cell viability of human lung and gastric cancer, increased DNA repair, and reduction of DNA damage caused by $\mathrm{H}_{2} \mathrm{O}_{2}$ (8). Our previous studies showed that phytochemicals, such as resveratrol, green tea, raspberry, and blueberry extract, exhibit anti-cancer properties and are potential radiosensitizers for various cancers, including melanoma (9-12). Our previous research also showed anti-tumor properties of kiwifruit extract (KE) on melanoma cells (13). Therefore, we hypothesize that anti-tumor effects of KE will synergize with RT to sensitize and amplify destruction of melanoma cells. This study is designed to explore that hypothesis and investigate the underlying molecular mechanisms behind the results. 


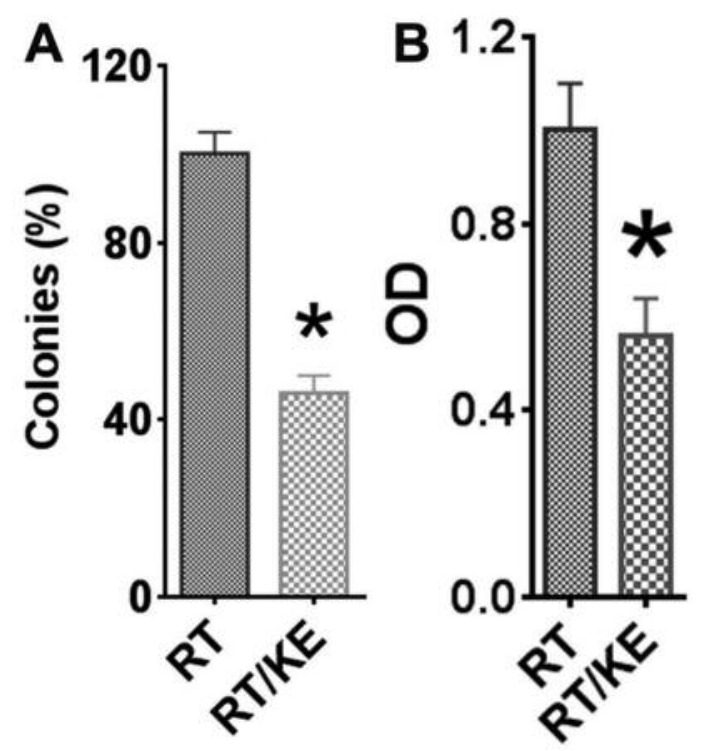

Figure 1. RT/KE's synergistic effect in inhibiting growth of CRL-11147 cells. Results, determined by using clonogenic assay and by using a proliferation kit, are expressed as the mean colony or optical density $(O D)+$ scanning electron microscopy in each group and represent two independent experiments. The asterisk $\left({ }^{*}\right)$ denotes a significant difference $(p<0.05)$ in the percentage of $(A)$ colonies in each group and (B) $O D$ in each group.

\section{Materials and Methods}

Tumor cell line. The human melanoma cell line, CRL-11147, was acquired from the America Type Culture Collection, Manassas, VA, USA. The cells were preserved in Dulbecco's Modified Eagle Medium and supplemented with $10 \%$ heat-inactivated fetal bovine serum and $1 \%$ penicillin-streptomycin, all acquired from Invitrogen, Carlsbad, CA, USA. The cells were then cultured at $37^{\circ} \mathrm{C}$ in a humidified $5 \% \mathrm{CO}_{2}$ incubator until $70 \%$ confluence prior to being subjected to experimental protocols.

Treatment with kiwifruit extract and radiation therapy. Seventy percent confluent CRL-11147 cells were treated with $50 \mu \mathrm{g} / \mathrm{ml}$ kiwifruit extract (Maple Lifesciences ${ }^{\mathrm{TM}}$, Kan Phytochemicals Private Limited, India) or $50 \mu \mathrm{g} / \mathrm{ml}$ medium alone for seventy-two $\mathrm{h}$, followed by radiotherapy (RT) at $4 \mathrm{~Gy}$. All RT was performed at $320 \mathrm{Kv}, 12.5 \mathrm{~mA}$, and $50 \mathrm{~cm}$ focus-to surface distance at $280 \mathrm{cGy} / \mathrm{min}$ dose rate with an aluminum filter using the XRAD 320 Biological Irradiator. RT dosage and KE concentration are based on our previous pilot experiments $(9$, 14-16). CRL-11147 cells in $75 \mathrm{~cm}^{2}$ culture flasks were irradiated at room temperature $(9,14)$. After completion of RT, CRL-11147 cells were cultured for an additional forty-eight $\mathrm{h}$ prior to harvest.

Clonogenic survival assay. Clonogenic survival assay was performed as detailed in our previous experiments $(9,10,17-19)$. The number of colonies was expressed as a percentage of total colonies $v s$. controls.

Immunohistochemistry (IHC). IHC staining for PCNA, TRAILR1, $\mathrm{P} 27$, Cyclin E, and CDK4 were completed as in our previously
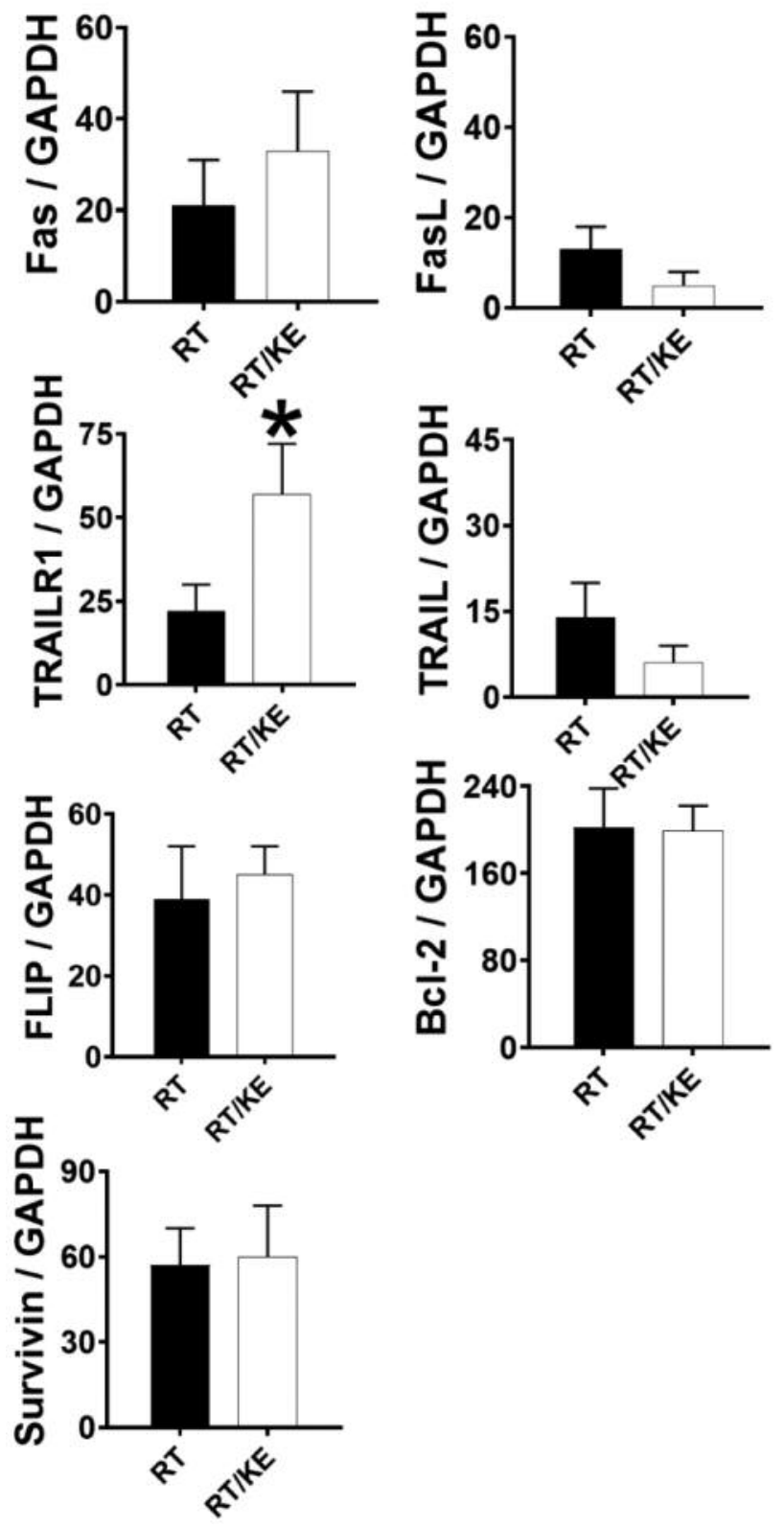

Figure 2. RT/KE's effect on the expression of pro- and anti-proliferative molecules investigated using reverse transcription-polymerase chain reaction. The experimental procedures were performed in triplicate and mRNA extraction was performed as described in the Materials and Methods section. Two independent experiments are represented by the results and displayed as the mean ratio of pro-and anti-proliferative molecule densitometric Units/GAPDH + scanning electron microscopy $(\times 100)$. The asterisk $(*)$ symbol denotes significant difference $(p<0.05)$ in mRNA expression of CRL-11147 cells treated with RT/KE or RT only.

published experiments $(10,20,21)$. MetaMorph version 6.3r6 (Molecular Devices Analytical Technologies, Sunnyvale, CA, USA) was used to quantify PCNA+ cells by random selection of 3-5 high power fields and manually counting. MetaMorph image analysis 


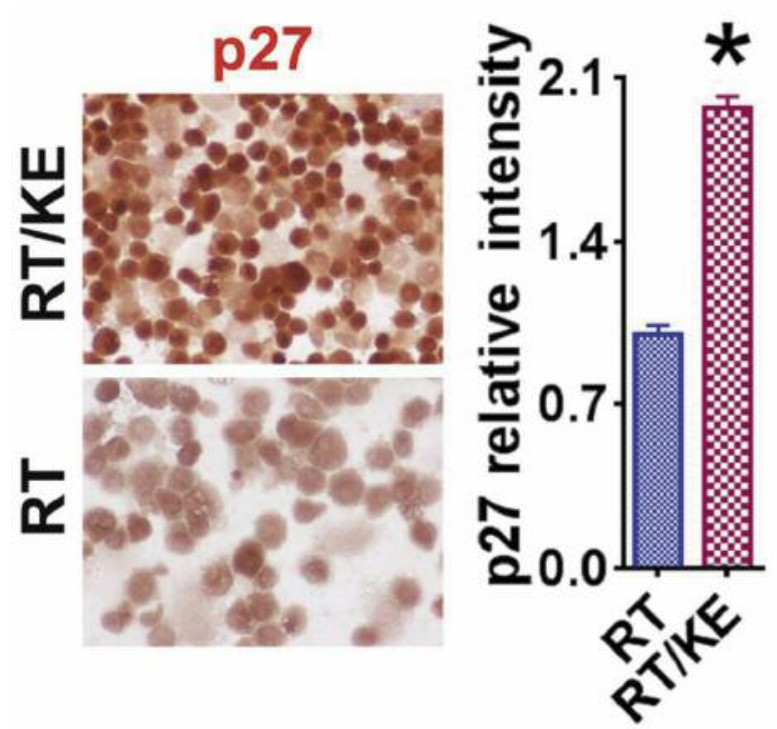

Figure 3. Effect of RT/KE on p27 expression evaluated by immunohistochemistry. The results are shown in the graph as the average integrated staining intensity of 3 slides + scanning electronic microscopy for $R T / K E v s$. RT. Significant difference $(p<0.05)$ is denoted by the asterisk (*). All results are representative of two independent experiments. Original magnification $\times 400$.

software was also used to obtain average staining intensity for proteins in the CRL-11147 cell-encompassed area. The results of are expressed as the average integrated staining intensity of 3 slides \pm SEM as compared to control cells.

Determination of proliferation using the Quick Cell Proliferation Assay Kit. Quick Cell Proliferation Assay Kit (BioVision, Milpitas, CA, USA) was used to examine cell proliferation. Increased activity of mitochondrial dehydrogenases reflected increased proliferation of viable cells. The increased activity resulted in increased detection of formazan dye by spectrophotometry. Protocol details can be found in our previously published studies $(9,17,18)$.

RT-PCR. CRL-11147 cells were washed and homogenized in TRIzol (Invitrogen, Waltham, MA, USA). RNA was extracted and reverse transcribed with $1 \mu \mathrm{g}$ of added RNA. Primer sequences and reverse transcription procedures were performed as outlined in our previous studies $(20,21)$.

Measurement of caspase-3 activity. CRL-11147 apoptosis was measured using caspase-3 activity. This was done using a caspase$3 / \mathrm{CPP} 32$ colorimetric assay kit (BioVision). Detailed process is described in our previous publications $(9,17)$.

Statistical analysis. Each experiment was repeated at least 3 times. An unpaired two-tailed student's $t$-test was used in statistical analysis. $p$-Values $<0.05$ were considered significant.

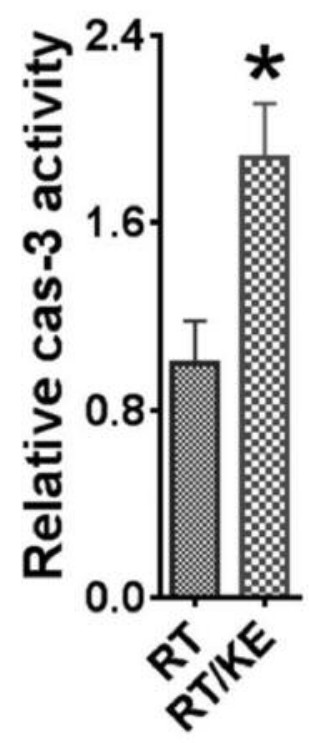

Figure 4. Caspase-3 activity was determined as described in the Materials and Methods section. Assays were performed in triplicate and results are displayed as the mean caspase-3 activity compared to controls + scanning electron microscopy. The asterisk (*) symbol denotes significant difference $(p<0.05)$ in the relative caspase-3 activity in CRL-11147 cells treated with RT/KE versus RT only. Images displayed represent two independent experiments.

\section{Results}

Effect of RT/KE on inhibition of melanoma cell proliferation. Forty-eight $\mathrm{h}$ after RT, clonogenic survival assay was used to evaluate CRL-11147 cell survival. When the RT/KE treated CRL-11147 cells were compared to the controls treated with RT only, the percentage of colonies were significantly lower (Figure 1A, $p<0.05$ ). These results were supported by OD values obtained using a Quick Cell Proliferation Assay Kit to assess cell proliferation (Figure 1B). The results strongly indicate that RT/KE displays synergism in inhibiting CRL11147 proliferation.

Effect of RT/KE on expression of pro-proliferative and antiproliferative molecules. To explore the mechanisms behind this result, mRNA expression of major pro- and antiproliferative molecules in the RT/KE and RT group were determined with RT-PCR (Figure 2). mRNA expression in both groups were mostly comparable except for antiproliferative molecule p27 and pro-proliferative molecule cyclin E, which were both increased significantly $(p<0.05)$. This finding was further investigated and confirmed at the protein level via p27 IHC staining (Figure 3). The staining intensity was stronger in the RT/KE group $v s$. RT group. 

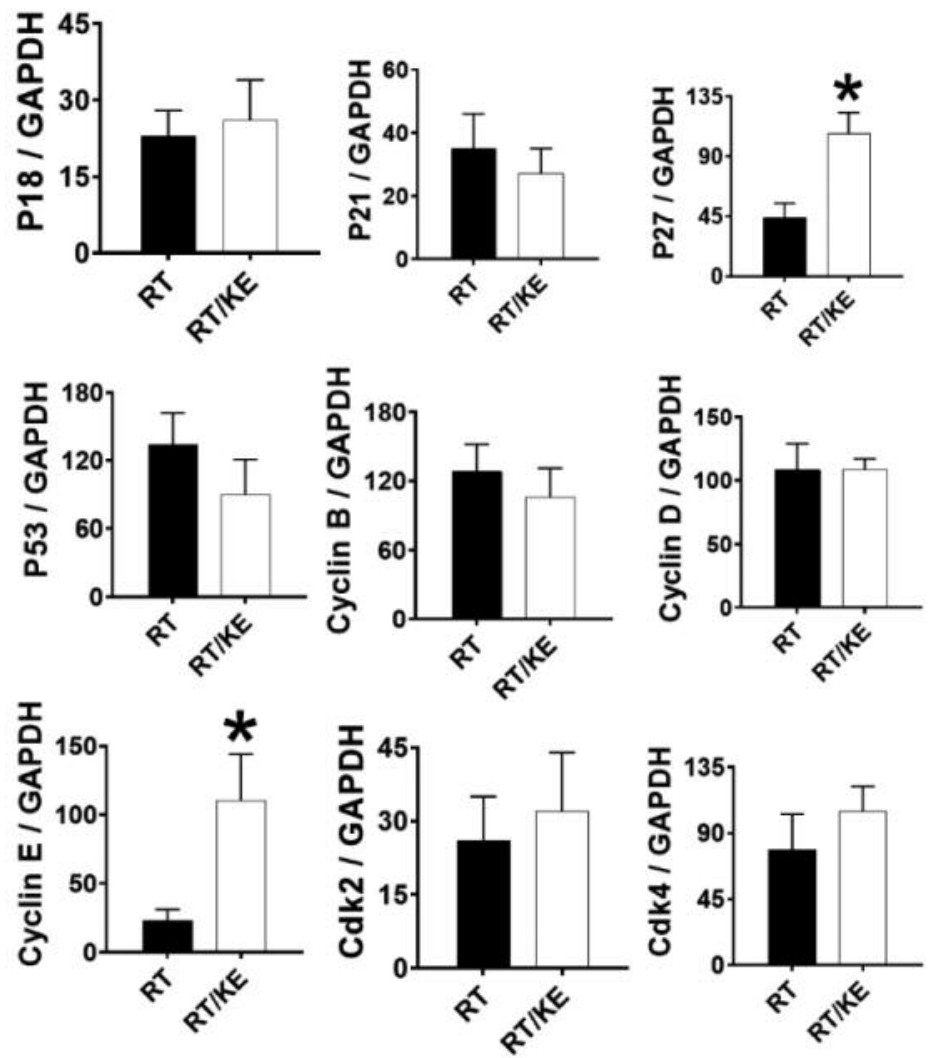

Figure 5. RT/KE's effect on the expression of pro- and anti-apoptotic molecules investigated using reverse transcription-polymerase chain reaction. The experimental procedures were performed in triplicate and mRNA extraction was performed as described in the Materials and Methods section. Two independent experiments are represented by the results and displayed as the mean ratio of pro-and anti-apoptotic molecule densitometric Units/GAPDH + scanning electron microscopy $(\times 100)$. The asterisk $\left(^{*}\right)$ symbol denotes significant difference $(p<0.05)$ in $m R N A$ expression of CRL11147 cells treated with RT/KE or RT only.

Surprisingly, the cyclin E mRNA expression levels were significantly increased in the RT/KE group $v s$. RT group. Cyclin $\mathrm{E}$ is an important molecule required to advance the cell cycle. Increase of cyclin $\mathrm{E}$ would increase cell proliferation; thus, favoring tumorigenesis. This would suggest that cyclin $\mathrm{E}$ did not play a major role in the growth inhibition effect displayed by RT/KE on CRL11147 cells. Altogether, the up-regulation of p27 corresponded with RT/KE's inhibitory effect on CRL-11147 cell survival.

RT/KE promotes apoptosis of CRL-11147 cells. To further elucidate the mechanisms behind RT/KE's anti-tumor effect on CRL-11147, a caspase-3 activity kit was used to investigate the possibility of increased apoptosis induced by RT/KE. Relative caspase-3 activity was increased in the $\mathrm{RT} / \mathrm{KE}$ group vs. RT group, which reflected increased apoptosis induced by RT/KE in CRL-11147 cells (Figure 4). This supported apoptosis as another mechanism behind RT/KE's inhibitory effect on CRL-11147 survival.
Effect of RT/KE on pro-apoptotic molecule TRAILR1 in CRL-11147 cells. To further investigate how RT/KE induced apoptosis in CRL-11147 cells, RT-PCR was used to determine mRNA expression of major pro- and antiapoptotic molecules. mRNA expression of these molecules was similar in both RT/KE and RT only groups, except TRAILR1, which was increased significantly in the RT/KE group $v s$. RT only group (Figure $5, p<0.05$ ). IHC staining confirmed this at the protein level (Figure 6). TRAILR1 is a pro-apoptotic molecule, and its increased expression correlates with increased apoptosis seen in RT/KE treated CRL-11147 cells.

\section{Discussion}

Surgical removal is the first-line treatment for early-stage melanoma and usually results in an excellent prognosis. Because melanoma is known as a radioresistant tumor, radiotherapy (RT) is rarely used as a primary treatment. 


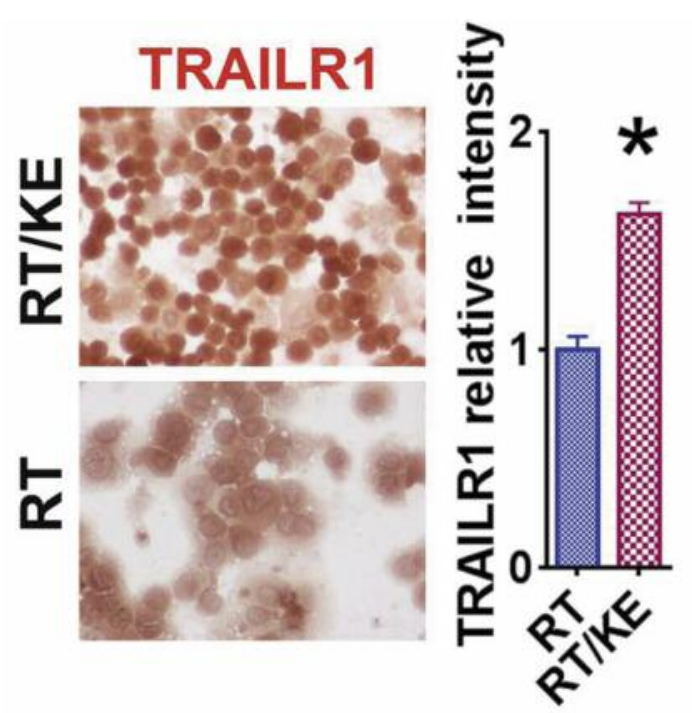

Figure 6. Effect of RT/KE on TRAILR1 expression evaluated by immunohistochemistry. The results are shown in the graph as the average integrated staining intensity of 3 slides + scanning electron microscopy for RT/KE vs. RT. Significant difference $(p<0.05)$ is denoted by the asterisk (*). All results are representative of two independent experiments. Original magnification $\times 400$.

Melanoma metastasizes to the brain in more than $50 \%$ of patients with advanced melanoma, making it the cancer with the highest rate of brain metastasis (22). Localized and/or whole-brain RT plays a significant role in the treatment of melanoma metastasis to the brain $(6,22)$. However, RT has a high risk of damaging healthy tissue leading to side-effects ranging from localized skin irritation to cutaneous scarring with tissue retraction and loss of skin appendages (23). Furthermore, it has been reported that while patients achieve better tumor control with RT, they have a high risk of developing neurocognitive decline $(24,25)$. Several studies have looked at possible radiosensitizers for treatment of melanoma with brain metastasis, but so far, none have demonstrated a survival benefit (26). KE may play a role in RT by increasing melanoma's susceptibility to radiation. This would decrease the dosages of radiation required for tumor control and attenuate the side effects.

This study shows that RT/KE was synergistic in inhibiting CRL-11147 survival via up-regulating anti-proliferative molecule p27 and pro-apoptotic molecule TRAILR1.p27, also known as Kip1, is a well-known tumor suppressor protein that regulates cell-cycle progression from G1 to Sphase via inhibition of cyclin $\mathrm{E}$ or cyclin dependent kinase (cdk) 2 complexes (27). p27 is active in the nucleus where it can suppress cdk. Once stimuli for mitosis occurs, some of the p27 is translocated to the cytoplasm allowing the cellcycle to progress (28). Decreased nuclear p27 and increased cytoplasmic p27 expression has been associated with melanoma progression from primary to dysplastic to subsequent metastasis $(29,30)$. Thus, the likely mechanism behind RT/KE's ability to decrease melanoma cell proliferation is the increased expression of p27 and its subsequent halting of the cell-cycle in the G1 phase.

Tumor necrosis factor-related apoptosis-inducing ligand receptor (TRAILR) also called death receptor 4, mediates apoptosis through the extrinsic apoptosis pathway once bound by TRAIL. The bound TRAILR initiates a cascade of signals and recruitment of various molecules, including the caspase- 8 and -10 (31). Caspases- 8 and -10 then cleave caspase- 3 causing its activation. Caspase-3, also known as the executioner caspase, is the common link between the intrinsic and extrinsic apoptotic pathways and is ultimately responsible for cell death induction (31). Thus, the increased apoptosis of RT/KE treated melanoma cells is likely mediated through the extrinsic apoptosis pathway secondary to the increased expression of TRAILR1. Prior studies from our lab showed that KE and IL-32 up-regulated TRAILR1 expression, while IL-9 up-regulated TRAIL expression in melanoma cells $(13,32,33)$. There is increased interest in targeting the TRAIL/TRAILR1 pathway for chemotherapy because it is effective in causing cancer cells apoptosis, while sparing healthy cells. Unfortunately, more studies are needed before clinical application as a chemotherapy agent (34-36). With the increased expression of TRAILR1 shown by RT/KE, a combination of chemotherapy and radiotherapy with radiosensitizers such as KE may open the doors to targeted chemotherapy of the TRAIL/TRAILR1 pathway.

One unexpected finding in our study was the increase of cyclin E. Similar unexplained variations in proliferative and apoptotic molecules were noted in our previous studies $(9$, $10,14,17,18)$. Cyclin $\mathrm{E}$ drives the cell cycle forward from $\mathrm{G}_{1}$ to $\mathrm{S}$ phase. The increase in Cyclin $\mathrm{E}$ seen in our study may be a cell adaptation to increase proliferation when faced with increased apoptosis. Another possible explanation may be suppression of pro-proliferative properties of cyclin $\mathrm{E}$ by increased p27 and TRAILR1. It is well documented that the cell cycle depends on a complex interaction of pro-/antiproliferative and apoptotic molecules (37). Undiscovered interactions between these molecules may be responsible for our results. Future research into the relationship between cyclin E and apoptosis may eventually reveal the reason behind our result.

In conclusion, $\mathrm{KE}$ acts as a radiosensitizer in melanoma cells by increasing the expression of anti-proliferative molecule p27 and pro-apoptotic molecule TRAILR1 in vitro. These data show potential for KE to augment RT of melanoma and possibly expand its current limited role in melanoma treatment. Future clinical studies are needed to determine the role of $\mathrm{RT} / \mathrm{KE}$ in the treatment of melanoma and other malignancies. 


\section{Conflicts of Interest}

The Authors declare that they have no conflicts of interest.

\section{Authors' Contributions}

Yujiang Fang designed the study. Yujiang Fang, Leon Kou, Ziwen Zhu, Emerson Fajardo, Qian Bai, Chase Redington, Huaping Xiao and Marco Lequio performed the experiments. Yujiang Fang, Ziwen Zhu and Mark R. Wakefield analyzed the data. Yujiang Fang, Ziwen Zhu, Mark R. Wakefield and Leon Kou interpreted the data. Leon Kou and Nelson Sham wrote the draft, and Yujiang Fang revised the manuscript critically.

\section{Acknowledgements}

This work was supported by Des Moines University for Yujiang Fang, grant number: IOER 112-3749. This research was supported in part by HCA Healthcare and/or an HCA Healthcare affiliated entity. The views expressed in this publication represent those of the author(s) and do not necessarily represent the official views of HCA Healthcare or any of its affiliated entities.

\section{References}

1 Tripp MK, Watson M, Balk SJ, Swetter SM and Gershenwald JE: State of the science on prevention and screening to reduce melanoma incidence and mortality: The time is now. CA Cancer J Clin 66(6): 460-480, 2016. PMID: 27232110. DOI: 10.3322/caac. 21352

2 Davis LE, Shalin SC and Tackett AJ: Current state of melanoma diagnosis and treatment. Cancer Biol Ther 20(11): 1366-1379, 2019. PMID: 31366280 . DOI: 10.1080/15384047.2019.1640032

3 Cohen JV, Tawbi H, Margolin KA, Amravadi R, Bosenberg M, Brastianos PK, Chiang VL, de Groot J, Glitza IC, Herlyn M, Holmen SL, Jilaveanu LB, Lassman A, Moschos S, Postow MA, Thomas R, Tsiouris JA, Wen P, White RM, Turnham T, Davies MA and Kluger HM: Melanoma central nervous system metastases: current approaches, challenges, and opportunities. Pigment Cell Melanoma Res 29(6): 627-642, 2016. PMID: 27615400. DOI: $10.1111 / \mathrm{pcmr} .12538$

4 Livingstone A, Agarwal A, Stockler MR, Menzies AM, Howard $\mathrm{K}$ and Morton RL: Preferences for immunotherapy in melanoma: a systematic review. Ann Surg Oncol 27(2): 571-584, 2020. PMID: 31664622. DOI: 10.1245/s10434-019-07963-y

5 Rubio-Rodríguez D, De Diego Blanco S, Pérez M and Rubio-Terrés C: Cost-effectiveness of drug treatments for advanced melanoma: a systematic literature review. Pharmacoeconomics 35(9): 879-893, 2017. PMID: 28551858. DOI: 10.1007/s40273-017-0517-1

6 Shi W: Radiation Therapy for Melanoma. In: Cutaneous Melanoma: Etiology and Therapy. Ward WH and Farma JM (eds.). Brisbane (AU), Codon Publications, 2017.

7 Johnson GE, Ivanov VN and Hei TK: Radiosensitization of melanoma cells through combined inhibition of protein regulators of cell survival. Apoptosis 13(6): 790-802, 2008. PMID: 18454317. DOI: 10.1007/s10495-008-0212-y

8 Lippi G and Mattiuzzi C: Kiwifruit and cancer: an overview of biological evidence. Nutr Cancer 72(4): 547-553, 2020. PMID: 31387399. DOI: $10.1080 / 01635581.2019 .1650190$
9 Fang Y, Bradley MJ, Cook KM, Herrick EJ and Nicholl MB: A potential role for resveratrol as a radiation sensitizer for melanoma treatment. J Surg Res 183(2): 645-653, 2013. PMID: 23522452. DOI: $10.1016 /$ j.jss.2013.02.037

10 Davidson KT, Zhu Z, Bai Q, Xiao H, Wakefield MR and Fang Y: Blueberry as a potential radiosensitizer for treating cervical cancer. Pathol Oncol Res 25(1): 81-88, 2019. PMID: 28963664. DOI: 10.1007/s12253-017-0319-y

11 Schroeder AC, Xiao H, Zhu Z, Li Q, Bai Q, Wakefield MR, Mann JD and Fang Y: A potential role for green tea as a radiation sensitizer for prostate cancer. Pathol Oncol Res 25(1): 263-268, 2019. PMID: 29101735. DOI: 10.1007/s12253-0170358-4

12 Sham N, Qin C, Zhu Z, Redington CG, Xiao H, Bai Q, Wakefield MR, Kou L and Fang Y: Raspberry extract with potential antitumor activity against cervical cancer. Anticancer Res 41(7): 3343-3348, 2021. PMID: 34230130. DOI: 10.21873/anticanres.15122

13 Kou L, Zhu Z, Redington C, Bai Q, Wakefield M, Lequio M and Fang Y: Potential use of kiwifruit extract for treatment of melanoma. Med Oncol 38(3): 25, 2021. PMID: 33586074. DOI: 10.1007/s12032-021-01465-2

14 Fang Y, DeMarco VG and Nicholl MB: Resveratrol enhances radiation sensitivity in prostate cancer by inhibiting cell proliferation and promoting cell senescence and apoptosis. Cancer Sci 103(6): 1090-1098, 2012. PMID: 22417066. DOI: 10.1111/j.1349-7006.2012.02272.x

15 Fang Y, Sharp GC and Braley-Mullen H: Interleukin-10 promotes resolution of granulomatous experimental autoimmune thyroiditis. Am J Pathol 172(6): 1591-1602, 2008. PMID: 18467701. DOI: 10.2353/ajpath.2008.071067

16 Fang Y, Yu S and Braley-Mullen H: TGF- $\beta$ promotes proliferation of thyroid epithelial cells in IFN- $\gamma(-/-)$ mice by down-regulation of p21 and p27 via AKT pathway. Am J Pathol 180(2): 650-660, 2012. PMID: 22119715. DOI: 10.1016/j.ajpath.2011.10.009

17 Fang Y, Herrick EJ and Nicholl MB: A possible role for perforin and granzyme B in resveratrol-enhanced radiosensitivity of prostate cancer. J Androl 33(4): 752-760, 2012. PMID: 22096086. DOI: 10.2164/jandrol.111.015164

18 Fang Y, Moore BJ, Bai Q, Cook KM, Herrick EJ and Nicholl MB: Hydrogen peroxide enhances radiation-induced apoptosis and inhibition of melanoma cell proliferation. Anticancer Res 33(5): 1799-1807, 2013. PMID: 23645724.

19 Zhu Z, Davidson KT, Brittingham A, Wakefield MR, Bai Q, Xiao $\mathrm{H}$ and Fang Y: Trichomonas vaginalis: a possible foe to prostate cancer. Med Oncol 33(10): 115, 2016. PMID: 27613161. DOI: 10.1007/s12032-016-0832-y

20 Fang Y, Sharp GC, Yagita H and Braley-Mullen H: A critical role for TRAIL in resolution of granulomatous experimental autoimmune thyroiditis. J Pathol 216(4): 505-513, 2008. PMID: 18810759. DOI: $10.1002 /$ path. 2428

21 Fang Y, Wei Y, Demarco V, Chen K, Sharp GC and BraleyMullen H: Murine FLIP transgene expressed on thyroid epithelial cells promotes resolution of granulomatous experimental autoimmune thyroiditis in DBA/1 mice. Am J Pathol 170(3): 875-887, 2007. PMID: 17322373. DOI: 10.2353/ajpath.2007.060816

22 Bafaloukos D and Gogas H: The treatment of brain metastases in melanoma patients. Cancer Treat Rev 30(6): 515-520, 2004. PMID: 15325032. DOI: 10.1016/j.ctrv.2004.05.001 
23 Singh M, Alavi A, Wong R and Akita S: Radiodermatitis: A review of our current understanding. Am J Clin Dermatol 17(3): 277-292, 2016. PMID: 27021652. DOI: 10.1007/s40257-0160186-4

24 Chang EL, Wefel JS, Hess KR, Allen PK, Lang FF, Kornguth DG, Arbuckle RB, Swint JM, Shiu AS, Maor MH and Meyers CA: Neurocognition in patients with brain metastases treated with radiosurgery or radiosurgery plus whole-brain irradiation: a randomised controlled trial. Lancet Oncol 10(11): 1037-1044, 2009. PMID: 19801201. DOI: 10.1016/S1470-2045(09)70263-3

25 Brown PD, Jaeckle K, Ballman KV, Farace E, Cerhan JH, Anderson SK, Carrero XW, Barker FG 2nd, Deming R, Burri SH, Ménard C, Chung C, Stieber VW, Pollock BE, Galanis E, Buckner JC and Asher AL: Effect of radiosurgery alone vs radiosurgery with whole brain radiation therapy on cognitive function in patients with 1 to 3 brain metastases: a randomized clinical trial. JAMA 316(4): 401-409, 2016. PMID: 27458945. DOI: $10.1001 /$ jama.2016.9839

26 Kim MM, Parmar H, Cao Y, Pramanik P, Schipper M, Hayman J, Junck L, Mammoser A, Heth J, Carter CA, Oronsky A, Knox SJ, Caroen S, Oronsky B, Scicinski J, Lawrence TS and Lao $\mathrm{CD}$ : Whole brain radiotherapy and $\mathrm{RRx}-001$ : Two partial responses in radioresistant melanoma brain metastases from a Phase I/II clinical trial: A TITE-CRM Phase I/II clinical trial. Transl Oncol 9(2): 108-113, 2016. PMID: 27084426. DOI: 10.1016/j.tranon.2015.12.003

27 Nickeleit I, Zender S, Kossatz U and Malek NP: p27kip1: a target for tumor therapies? Cell Div 2: 13, 2007. PMID: 17488529. DOI: $10.1186 / 1747-1028-2-13$

28 Ivan D, Diwan AH, Esteva FJ and Prieto VG: Expression of cell cycle inhibitor p27Kip1 and its inactivator Jab1 in melanocytic lesions. Mod Pathol 17(7): 811-818, 2004. PMID: 15154004. DOI: $10.1038 /$ modpathol.3800123

29 Chen G, Cheng Y, Zhang Z, Martinka M and Li G: Prognostic significance of cytoplasmic p27 expression in human melanoma. Cancer Epidemiol Biomarkers Prev 20(10): 2212-2221, 2011. PMID: 21828232. DOI: 10.1158/1055-9965.EPI-11-0472
30 Li Q, Murphy M, Ross J, Sheehan C and Carlson JA: Skp2 and p27kip1 expression in melanocytic nevi and melanoma: an inverse relationship. J Cutan Pathol 31(10): 633-642, 2004. PMID: 15491322. DOI: 10.1111/j.0303-6987.2004.00243.x

31 Wang S and El-Deiry WS: TRAIL and apoptosis induction by TNF-family death receptors. Oncogene 22(53): 8628-8633, 2003. PMID: 14634624. DOI: 10.1038/sj.onc.1207232

32 Fang Y, Chen X, Bai Q, Qin C, Mohamud AO, Zhu Z, Ball TW, Ruth CM, Newcomer DR, Herrick EJ and Nicholl MB: IL-9 inhibits HTB-72 melanoma cell growth through upregulation of p21 and TRAIL. J Surg Oncol 111(8): 969-974, 2015. PMID: 25988864. DOI: $10.1002 /$ jso.23930

33 Nicholl MB, Chen X, Qin C, Bai Q, Zhu Z, Davis MR and Fang Y: IL-32 $\alpha$ has differential effects on proliferation and apoptosis of human melanoma cell lines. J Surg Oncol 113(4): 364-369, 2016. PMID: 27100023. DOI: 10.1002/jso.24142

34 Gerspach J, Pfizenmaier K and Wajant H: Therapeutic targeting of CD95 and the TRAIL death receptors. Recent Pat Anticancer Drug Discov 6(3): 294-310, 2011. PMID: 21762072. DOI: $10.2174 / 157489211796957739$

35 de Vries EG, Timmer T, Mulder NH, van Geelen CM, van der Graaf WT, Spierings DC, de Hooge MN, Gietema JA and de Jong S: Modulation of death receptor pathways in oncology. Drugs Today (Barc) 39(Suppl C): 95-109, 2003. PMID: 14988748.

36 Nagane M, Huang HJ and Cavenee WK: The potential of TRAIL for cancer chemotherapy. Apoptosis 6(3): 191-197, 2001. PMID: 11388668. DOI: 10.1023/a:1011336726649

37 Johnson DG and Walker CL: Cyclins and cell cycle checkpoints. Annu Rev Pharmacol Toxicol 39: 295-312, 1999. PMID: 10331086. DOI: 10.1146/annurev.pharmtox.39.1.295

Received September 29, 2021

Revised October 23, 2021

Accepted November 3, 2021 